\title{
EFFeCtS OF THE 1988 Fires on Aquatic Systems of Yellowstone National Park
}

\author{
Christopher T. Robinson • Deron E. Lawrence • G. Wayne Minshall \\ Stream Ecology Center - Department of Biological Sciences - Idaho State University \\ PocATELlo
}

\begin{abstract}
Collections and measurements were made in August 1990 at the same site locations as in 1988 and 1989 (Table 1). All the information specified in our research proposal for year 1990 was obtained except for some transport and water chemistry samples. These data are being incorporated with data collected in 1988 and 1989 for evaluation of temporal trends. The status of the various measurements and sample collections is given in Table 2. All of the physical and chemical determinations have been completed through the tabulation stage and initial statistical or graphical data analysis. Also note that water chemical analyses are less complete than previous years with only alkalinity, hardness, specific conductance, $\mathrm{pH}$, nitrogen and phosphorus being analyzed in 1990 due to funding restrictions. The processing of all periphyton samples (as chlorophyll a and AFDM, N=110) is complete. All collected organic matter transport samples (as CPOM and FPOM, N=80) have been processed and categorized for organic matter type.
\end{abstract}

Transport samples were not collected at Cache Creek 3rd, 4th order, South Cache 3rd order, and Soda Butte 4th order sites due to rainstorms which produced high inorganic sediment loads and caused the nets to clog. As anticipated, the processing of benthic macroinvertebrate samples with the quantification and characterization of associated benthic organic matter (BOM) are only partially complete at this time (Table 2). Of the 110 samples collected (5/site * 22 sites), 90 samples still need to be processed. Stream profiles still need to be digitized for calculating bankfull channel areas and consequently bankfull discharge values. Woody debris maps for the 1991 field season are being prepared.

\section{$\downarrow$ Biological Relationships}

The transport data indicate an increase in both CPOM and FPOM in 1st order burn sites from 10/88 to $8 / 90$ (Figure 1). The quantity of CPOM and FPOM decreased slightly in 2 nd order burn sites in $8 / 90$ from $8 / 89$, although the quantity still was greater in the burn sites than in 2 nd order reference sites in $8 / 90$. The quantity of CPOM decreased in 1990 from 1989 to comparable values found in 1988 in 2nd order reference sites, while FPOM values were comparable among years. CPOM and FPOM decreased in 1990 from 1989 in 3rd and 4th order burn sites to values found in 3rd and 4th order reference sites (Figure 1). The characterization of the CPOM and FPOM indicate a substantial decrease in the \% charcoal in all burn sites from 1989 to 1990 , suggesting that much of the transported CPOM and FPOM was derived from new riparian growth (Figure 2).

Periphyton levels were somewhat greater in the 1st, 2nd, and 3rd order burn sites in 1990 over values in 1989 as indicated by chlorophyll a levels (Figure 3). Chlorophyll a levels remained unchanged in 2 nd and 
BURNED WATERSHEDS

BLACKTAIL CREEK-WFK 1B BLACKTAIL CREEL-EFK

CACHE (noname)

FAIRY CREEK

TWIN CREEK
$1 \mathrm{~B}$

$1 \mathrm{~B}$

$1 \mathrm{~B}$

$1 \mathrm{~B}$
COORDINATES

$1017-22$
101705
1033221001
20180803
103323

BLACKTAIL CREEK-MAIN2B

CACHE (noname) UPPER 2B

CACHE (noname) LOWER 2B

FAIRY CREEK

IRON SPRINGS CREEK

2B

2B
1017-21

10332210

10332206

201808

20181604
110 '35";44'53"

110 '35";44'53"

110 '03";44'51"

$110^{\prime} 52^{\prime \prime} ; 44^{\prime} 32^{\prime \prime}$

$110^{\prime} 10^{\prime \prime} ; 44^{\prime} 48^{\prime \prime}$
UTM

4973.1N, 532.8E

4973.5N, 534.3E

$4966.3 \mathrm{~N}, 575.8 \mathrm{E}$

$4930.3 \mathrm{~N}, 511.7 \mathrm{E}$

$4962.3 \mathrm{~N}, 567.5 \mathrm{E}$

$\begin{array}{lllll}\text { CACHE CREEK } & \text { 3B } & 103322-22 & 110^{\prime} 04^{\prime \prime} ; 44^{\prime} 51^{\prime \prime} & 4965.5 \mathrm{~N}, 573.2 \mathrm{E} \\ \text { HELLROARING CREEK } & \text { 3B } & 1026-22 & 110^{\prime} 23^{\prime \prime} ; 45^{\prime} 10^{\prime \prime} & 5001.7 \mathrm{~N}, 548.6 \mathrm{E} \\ \text { IRON SPRINGS CREEK } & \text { 3B } & 201816 & 110^{\prime} 51^{\prime \prime} ; 44^{\prime} 27^{\prime \prime} & 4922.8 \mathrm{~N}, 511.7 \mathrm{E} \\ \text { LAVA CREEK } & \text { 3B } & 100705 & 110^{\prime} 38^{\prime \prime} ; 45^{\prime} 56^{\prime \prime} & 4976.0 \mathrm{~N}, 529.7 \mathrm{E}\end{array}$

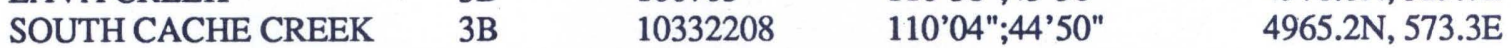

$\begin{array}{lllll} & & & \\ \text { CACHE CREEK } & \text { 4B } & 103322-21 & 110^{\prime} 05^{\prime \prime} ; 44^{\prime} 50^{\prime \prime} & 4965.0 \mathrm{~N}, 572.7 \mathrm{E} \\ \text { HELLROARING CREEK } & \text { 4B } & 1026-21 & 110^{\prime} 23^{\prime \prime} ; 5^{\prime} 09^{\prime \prime} & 5000.2 \mathrm{n}, 548.4 \mathrm{E} \\ \text { LAMAR RIVER } & \text { 4B } & 1033-22 & 110^{\prime} 08^{\prime \prime} ; 44^{\prime} 48^{\prime \prime} & 4962.5 \mathrm{~N}, 567.6 \mathrm{E}\end{array}$

\section{UNBURNED WATERSHEDS}

$\begin{array}{lllll}\text { AMPHTHEATER CREEK } & 2 & 10331714 & 110^{\prime} 04^{\prime \prime} ; 44^{\prime} 56^{\prime \prime} & 4974.3 \mathrm{~N}, 571.9 \mathrm{E} \\ \text { ROSE CREEK } & 2 & 103312 & 110^{\prime} 13^{\prime \prime} ; 44^{\prime} 54^{\prime \prime} & 4972.0 \mathrm{~N}, 561.2 \mathrm{E} \\ \text { PEBBLE CREEK } & 3 & 10331713 & 110^{\prime} 07^{\prime \prime} ; 44^{\prime} 56^{\prime \prime} & 4976.0 \mathrm{~N}, 570.0 \mathrm{E} \\ \text { SODA BUTTE CREEK } & 4 & 103317 & 110^{\prime} 10^{\prime \prime} ; 44^{\prime} 52^{\prime \prime} & 4968.5 \mathrm{~N}, 565.7 \mathrm{E}\end{array}$

Table 1. Stream research sites for Yellowstone National Park wildfire study (SONYEW $=$ System of Numbering Yellowstone Waters (Mahony and Lentsch 1986); UTM = Universal Mercator Map coordinate system). 


\begin{tabular}{|c|c|c|c|}
\hline & Samples or Measurements & Data & Data \\
\hline $\begin{array}{l}\text { Variable } \\
\text { Analyzed }\end{array}$ & Processed/Total Obtained & Entered & Reduced \\
\hline \multicolumn{4}{|l|}{ Physical } \\
\hline ure, annual range & $22 / 22$ & 22 & 22 \\
\hline Discharge & $22 / 22$ & 48 & 48 \\
\hline Channel Gradient & $220 / 220$ & 220 & 220 \\
\hline Cross-section Profiles & $60 / 110$ & 60 & 60 \\
\hline Velocity & $2200 / 2200$ & 2200 & 2200 \\
\hline Substratum Particle Size & $2200 / 2200$ & 2200 & 2200 \\
\hline Embeddedness & $2200 / 2200$ & 2200 & 2200 \\
\hline Retention Devices & \multicolumn{3}{|l|}{22 sites mapped } \\
\hline Riparian/Channel Conditions & $110 / 110$ & 110 & NA \\
\hline \multicolumn{4}{|l|}{ Chemical } \\
\hline General Properties & $22 / 22$ & 22 & 22 \\
\hline Major Specific Ions & $22 / 22$ & 22 & 22 \\
\hline \multicolumn{4}{|l|}{ Biological } \\
\hline \multicolumn{4}{|l|}{ Periphyton } \\
\hline AFDM & $110 / 110$ & 110 & 110 \\
\hline $\mathrm{Chl} \mathbf{a}$ & $110 / 110$ & 110 & 110 \\
\hline Benthic Invertebrates & $20 / 110$ & 0 & 0 \\
\hline \multicolumn{4}{|l|}{ Benthic Organic Matter } \\
\hline AFDM & $20 / 110$ & 0 & 0 \\
\hline$\%$ Charcoal & $20 / 110$ & 0 & 20 \\
\hline \multicolumn{4}{|l|}{ Transported Organic Matter } \\
\hline AFDM & $80 / 80$ & 80 & 80 \\
\hline$\%$ Charcoal & $80 / 80$ & 80 & 80 \\
\hline \multicolumn{4}{|c|}{$\begin{array}{l}\text { Table } 2 . \text { Summary of measurements made in } 1990 \text { and status of data processing and analysis. (NA = Not } \\
\text { Applicable) }\end{array}$} \\
\hline
\end{tabular}



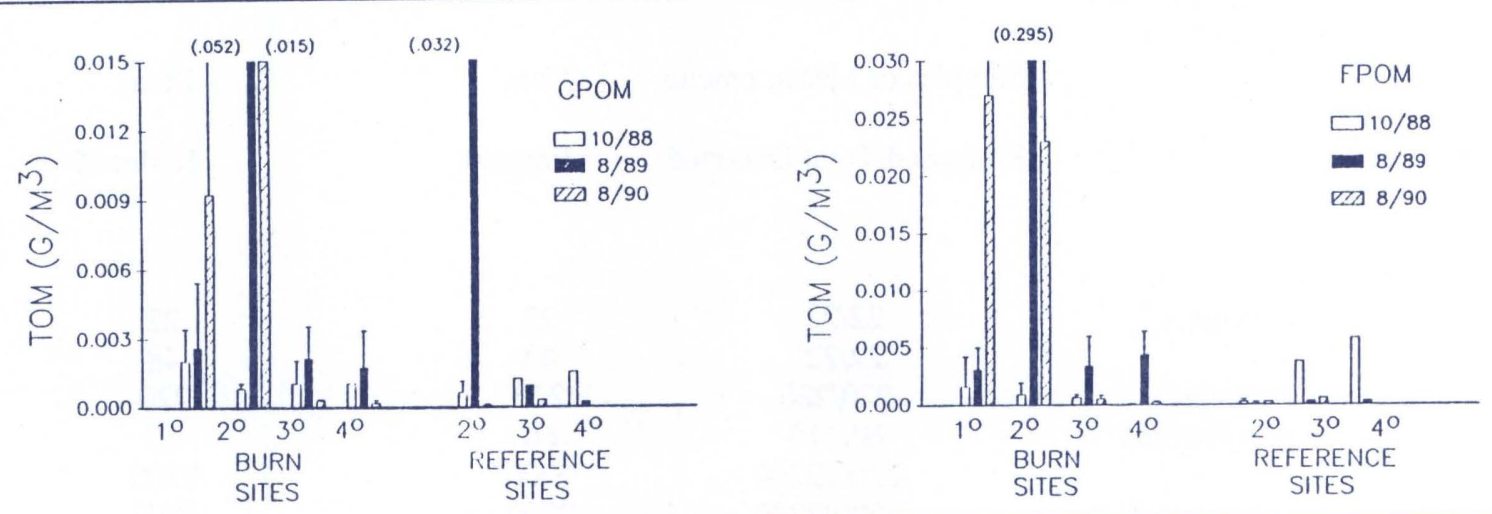

Figure 1. Transported organic matter ( $/ \mathrm{m} 3$ ) as coarse (CPOM) or fine (FPOM) particulate organic matter in burn or unvurned stream study sites. Numbers represent respective stream orders. Bars represent one standard deviation. Sample size equals five sites (2 samples per site) for burn streams orders 1-3, three sites for burn stream 4 th order, two sites for unburn 2 nd order, and one site for unburn 3 rd and 4 th order study streams. Numbers in parenthesis represent values outside range of graph.

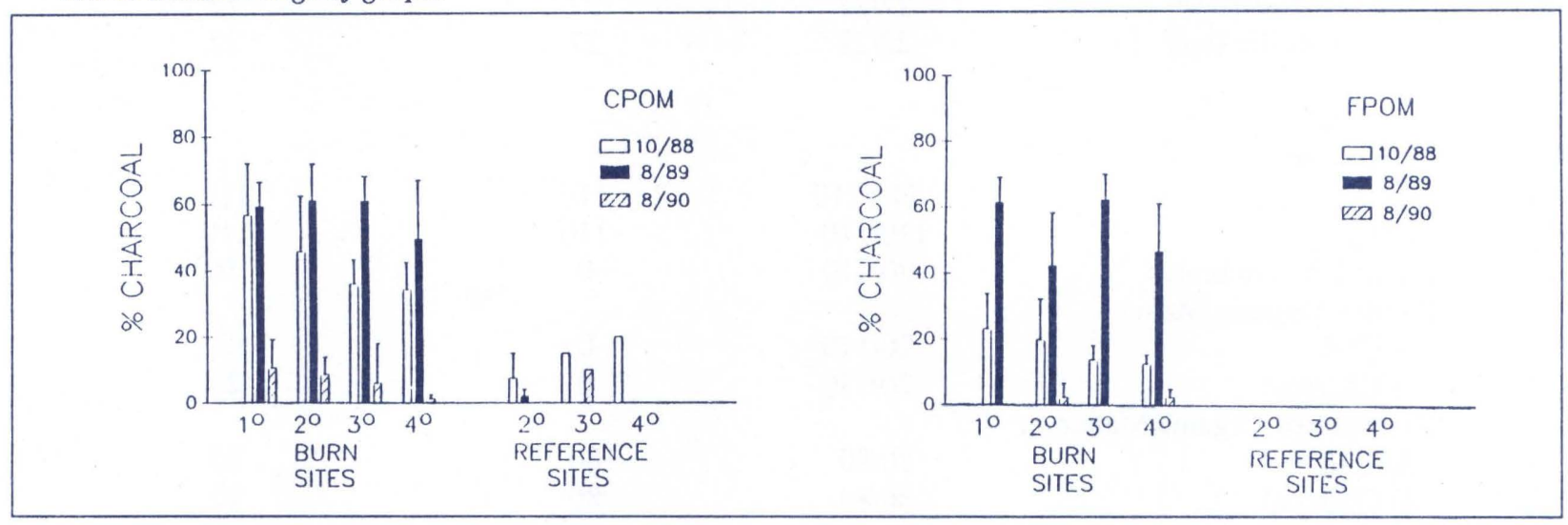

Figure 2. The percent charcoal comprising transported organic matter. Bars represent one standard error of the mean. Sample size as in figure 1.

3rd order reference sites, and increased in the 4th order reference site in 1990. The AFDM of periphyton was similar or unchanged in 1990 from those in 1989 burn and reference sites. The AFDM (biomass) to chlorophyll a ratio (B/C index) decreased in 1990 from values observed in 1989 suggesting an even greater degree of autotrophy in 1990 than in 1989.

Woody debris maps were drawn for two $50 \mathrm{~m}$ reaches at each site during both 1989 and 1990. All wood larger than $40 \mathrm{~cm}$ long or $2 \mathrm{~cm}$ diameter was recorded. The following characteristics were measured or noted for each piece of wood: its source, whether it had fallen directly from the riparian zone or had floated to its location; the probability the piece of wood will move on a scale of 1-5; the wood orientation, ("drift" is contained within the channel, "ramp" was partially in the channel "bridge" crossed the stream channel, "overhang" leaned over the channel from the bank without touching the substrate, "debris dam" consisted of smaller debris, mud, and gravel piled together; and "new since fire" (NSF) if it appeared the piece had entered the stream since the 1988 fires and was charred). In the field we worked with the premise that all wood was in the stream prior to 1988 , and gathered evidence to contradict this if a piece was placed in the "NSF" category. 

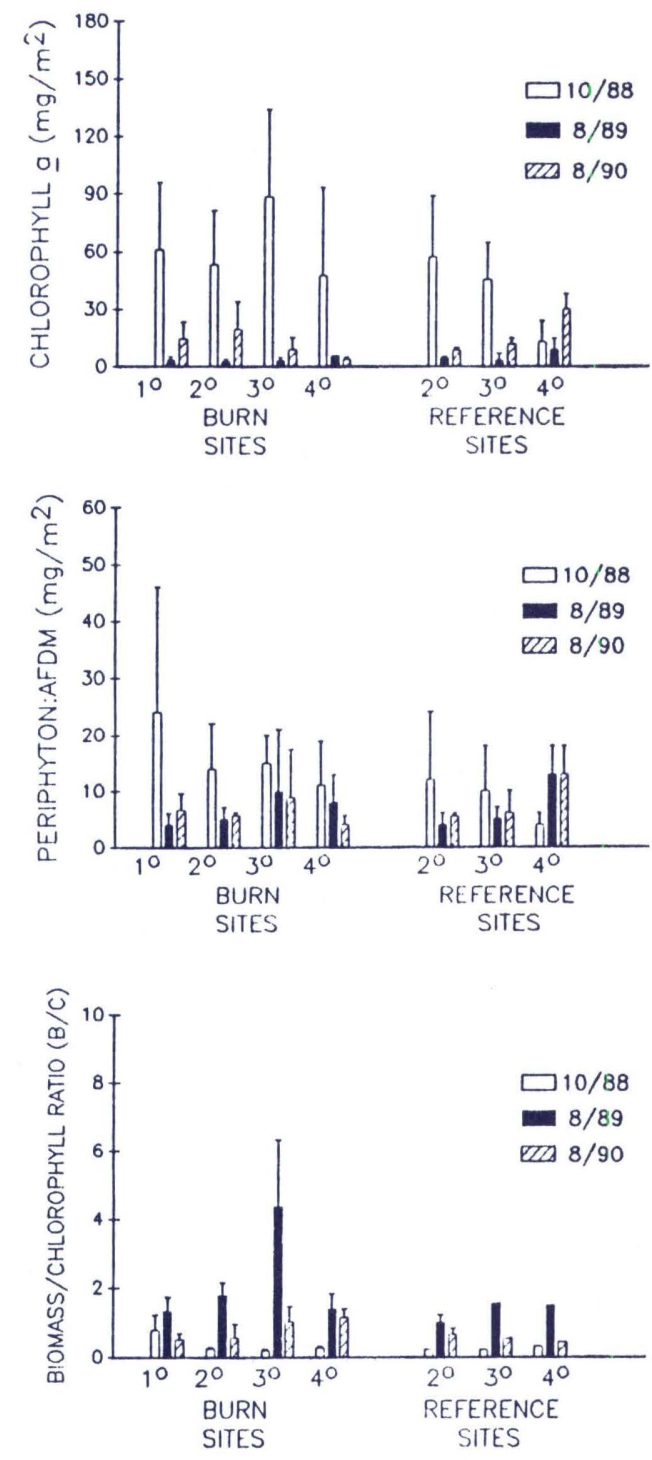

Figure 3. Periphyton characteristics as chlorophyll a $(\mathrm{mgl}$ $\left.\mathrm{m}^{2}\right), A F D M\left(\mathrm{mg} / \mathrm{m}^{2}\right)$, and biomass/chlorophyll ratio $(B / C)$ for the Yellowstone National Park study streams in October 1988, August 1989, and August 1990. Bars represent 1 standard deviation. Sample size equals 5 sites (5 samples/site) for 1st, 2nd, and 3rd order burn streams, three sites for 4th order burn stream, two sites for 2nd order unburn stream, and one site each for $3 r d$ and 4 th order unburn streams.
In every stream more wood was present in 1990 than in 1989, but burn streams showed more dramatic change than reference streams. Among burn streams the 2nd order sites displayed the greatest gross change (pieces lost in 1989 added to those gained in 1990), and we attribute this to the maximized combination of high flow discharge and stream/riparian zone interaction. The 1st order site had the greatest riparian zone effect, but high flows were not sufficient to move many pieces of wood. Third order sites had enough power during high flow to move larger pieces of wood, but relatively few pieces of wood entered from the riparian zone. Fourth order sites removed nearly all wood from the channel except those pieces protected along the stream banks, so wood entering from the riparian zone becomes more important than in the 3rd order sites.

Wood contained within the channel (drift) was more common than any other group, in both burn and reference streams. Fourth order sites showed the fewest pieces of drift, most likely because the high flows are able to carry away nearly anyunattached piece of wood in the channel. Drift is the least stable type of wood found in these streams, and probably doesn't offer a high amount of stabilization to the burn streams until many pieces combine to form debris dams.

The number of "NSF" pieces in each site and year represent the new pieces entering the reach during the previous year. Second order sites had the greatest number of new pieces, followed by 1 st, $3 \mathrm{rd}$, then 4 th

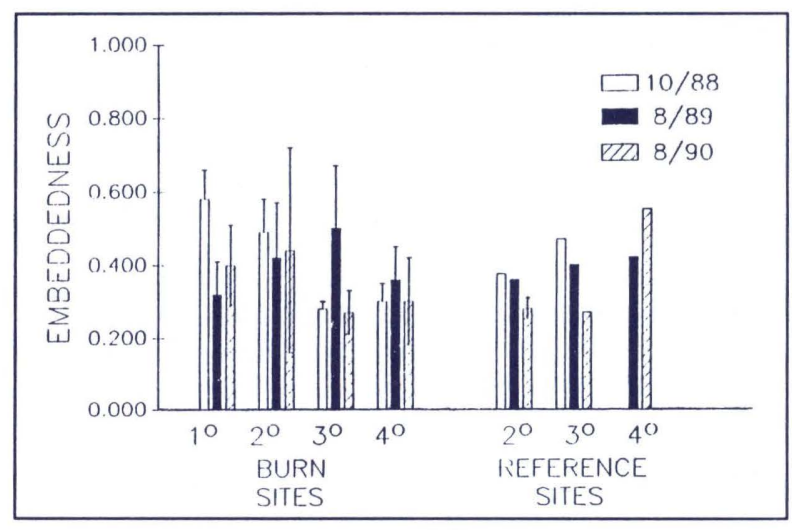

Figure 4. Mean embeddedness (+1 std err) for burn and reference study sites of the Yellowstone National Park fire study in October 1988, August 1989, and August 1990. 
order sites. In every case more new pieces entered the streams during 1988-1989 than during 1989-1990. Yellowstone Park has been experiencing average spring runoff, and until higher than average peak-flows occur, wood probably will continue to accrue within these stream channels. At that point much of the wood gained in channels will probably be removed by stream flow, and moreso in the burn stream sites than in the reference sites.

\section{Physical and Chemical RELATIONSHIPS}

Five transects were mapped from each study stream for determination of channel profile changes, with one representative cross-section from each stream presented in this report. Little change in channel morphology was observed for most sites as indicated by cross-section profiles. Of 1st order sites additional bed cutting was evident in West Fork Blacktail Deer Creek and Twin Creek in 1990. A small degree of bed movement (e.g. bed filling) was observed for the other 1st order burn sites (Cache Creek in particular), while the reference site, Rose Creek, displayed no change. Fairy Creek, a low gradient system, also displayed no change.

Channel profiles of 2 nd order study sties indicate little change, although bed filling was present at Mainstem Blacktail Deer Creek. Upper Cache Creek displayed a small amount of channel cutting in 1990, although most of the cutting at this site occurred in 1989. Essentially no change was observed in low gradient 2nd order burn sites (Fairy Creek and Iron Springs Creek). The reference stream (Amphitheater Creek) displayed some bed cutting.

Channel profiles of 3rd order sites indicate no change in Lava Creek, Iron Springs Creek, South Fork Cache Creek, and the reference stream Pebble Creek. Both Cache Creek and Hellroaring Creek burn sites displayed additional channel changes in 1990 from those observed in 1989. Of the 4th order sites, only Hellroaring Creek displayed substantial channel movement in 1990 compared to those observed in 1989. The Hellroaring system, in general, is still showing major channel cutting and some lateral movement.
Mean baseflow channel width, estimated from 5 transects at each site, remained essentially unchanged in 1990 from values observed in 1989. Baseflow discharge was greater in 1990 than in 1989 atmost sites, with the notable exception of Cache Creek 1st order. Of note, is that major rain/runoff events did occur during the 1990 sampling period and may have influenced baseflow discharge calculations. No changes were observed in the \% slope among years at any site.

Mean current velocities tended to be greater in 1990 than in 1989 at most sites, suggesting stream flows were higher or channel gradients greater in 1990 . The coefficients of variation (CV) for current velocities continued to decrease or remain about the same in the burn sites to values similar to reference sites from 1989 to 1990 . Of interest is that the CV for current velocity st 3rd order Hellroaring Creek increased in 1990 over values found in 1989, thus supporting the observed channel changes at this site. No substantial changes were observed for mean substrate size, with most values being similar to values found in 1989. Coefficients of variation for substrate size for 1990 also were similar to values found in 1989. The mean embeddedness remained unchanged in 1st, 2nd, and 3rd order burn sites, and decreased in 3rd order burn sites from 1989 to 1990 (Figure 4). Mean embeddedness was unchanged in 2 nd order reference sites, decreased in the 3rd order reference site (Pebble Creek), and slightly increased in the 4th order reference site (Soda Butte). These data suggest that the influx of particles into 3rd order burn sites in 1989 were removed in 1990.

Ortho-phosphate levels decreased in 1990 in 1st, 2nd, and 3rd order burn streams, while remaining unchanged or increasing slightly in 4th order burn streams. Ortho-phosphate levels remained unchanged in Amphitheater Creek (2nd order reference site) and decreased in Rose Creek (2nd order burn site) and slightly decreased in Pebble Creek (3rd order reference stream). Alkalinity and hardness values decreased in 1st, 2nd, and 3rd order burn streams in 1990 from values in 1989. These values decreased only in Cache Creek for the 4 th order burn streams. In contrast, nitrogen levels (as NH4 and NO3 increased in 1st, 2nd, and 3rd order burn streams, and increased in 4th order Hellroaring Creek. Nitrogen levels decreased in the other 4th order burn sites. Nitrogen levels decreased in 2nd order reference sites, and increased in the 3rd order reference stream. 